\title{
Multiyear rainfall variability in the Mono river basin and its impacts on Nangbeto hydropower scheme
}

\author{
Salomon Obahoundje ${ }^{1}$, Ernest Amoussou ${ }^{2}$, Marc Youan Ta $^{3}$, Lazare Kouakou Kouassi ${ }^{4}$, and \\ Arona Diedhiou ${ }^{1,5}$ \\ ${ }^{1}$ LASMES - African Centre of Excellence on Climate Change, Biodiversity and Sustainable Development, \\ Université Félix Houphouët Boigny, Abidjan, Côte d'Ivoire \\ ${ }^{2}$ Département de Géographie et Aménagement de Territoire (DGAT/FLASH), \\ Université de Parakou, Parakou, Bénin \\ ${ }^{3}$ Centre Universitaire de Recherche et d'Application en Télédétection (CURAT), \\ Université Félix Houphouët Boigny, Abidjan, Côte d'Ivoire \\ ${ }^{4}$ UFR-Environnement, Université Jean Lorougnon GUEDE, 12 BP V 25 Daloa 12, Côte d'Ivoire \\ ${ }^{5}$ Univ. Grenoble Alpes, IRD, CNRS, Grenoble INP, IGE, 38000 Grenoble, France
}

Correspondence: Salomon Obahoundje (obahoundjes@yahoo.com)

Published: 16 November 2021

\begin{abstract}
Hydropower energy, the main renewable energy source in West Africa, contributes to more than half of the Togo and Benin National electrification. This resource highly depends on water availability in rivers or reservoirs. The water availability heavily relies on climate patterns of the area. In the climate change context, the sustainability of hydropower plants is at risk. This work aims to assess the sensitivity of the Nangbeto hydropower plant to multiyear climate variability using statistical analysis. The results show that energy generation at Nangbeto hydropower is more modulated by four main variables namely inflow to reservoir, water level, rainfall of the actual and the previous year. The energy generation is found to be strongly and significantly correlated to inflow to reservoir, water level, and rainfall. Overall, the Nangbeto hydropower generation is more sensitive to inflow which is controlled by climate variables (rainfall, temperature) and land use/cover change. Therefore, the probable future change in these variables is suggested to be deeply investigated.
\end{abstract}

\section{Introduction}

The Mono basin plays a vital role in the socio-economic development of Togo and Benin countries. This basin is subjected to different water uses activities namely agriculture, livestock breeding, as well as small dam and Nangbeto hydropower generation. Nangbeto dam was constructed in 1987 to power Togo and Benin in electricity. This source has recorded rapid growth over the world especially over West African countries (IHA, 2019). In Togo, hydropower energy represents more than $80 \%$ of the total electric energy consumption of the country which occupies more than $98 \%$ share of renewable energy generation. The main challenge is that this source depends on water availability which is a function of climate variables. Thus, any change or variability in climate factors could affect hydropower plant (IHA, 2019; Rim, 2019) generation.

The water availability relies on precipitation and potential evapotranspiration which is a function of temperature. Therefore, any change in rainfall and temperature could affect the water availability for power generation (Hamududu and Killingtveit, 2012, 2016). It has been proven that West Africa's temperature has significantly increased over the past ranging from 0.3 to 1 and 0.2 to $0.5^{\circ} \mathrm{C}$ over the Gulf of Guinea and this could be amplified in the future (Riede et al., 2016). The rising in temperature consequently leads to in increase the PET. However, the past and future changes of precipitation are uncertain and this change occurring faster than ever before (Riede et al., 2016). This could make the prediction of hydropower uncertain and may vary depending 


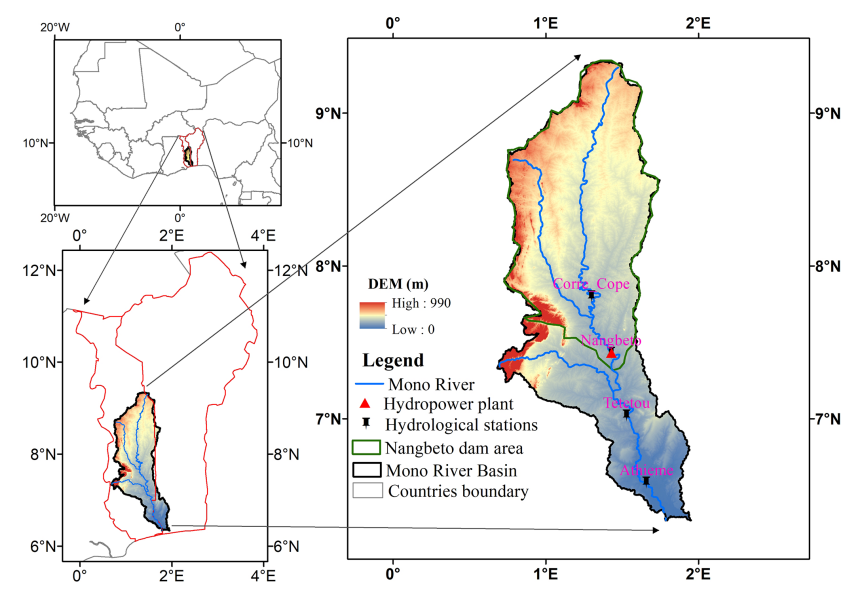

Figure 1. Presentation of Mono basin.

on the geographical location of the dam (Cole et al., 2014; Kling et al., 2016). Knowing the past could help us to learn the lesson and develop measures to adapt for the future.

This study has the goal of assessing the sensitivity of Nangbeto energy generation to change and variability of past temperature and precipitation over the 1988-2016 period. The observed rainfall, energy generation, inflow to reservoir, outflow as turbined water, and reservoir water level dataset as well as temperature were analysed. Aside from the general introduction which gives the state of the art concerning the topic, the study area, as well as the data and method used are described. Afterward, the results are presented and discussed following by a conclusion and some recommendations.

\section{Study area, data and methods}

\subsection{Study area}

Mono basin, transboundary river basin sharing between Togo and Benin, covers an area of $24282.26 \mathrm{~km}^{2}$. In Mono basin is constructed Nangbeto hydropower plant with an installed capacity of $65 \mathrm{MW}$ (Fig. 1). The population living in the basin are mainly rural and their main activity is agriculture which exposes the basin under a rapid land cover/use dynamic (Obahoundje et al., 2018).

The cumulative annual precipitation in the basin is estimated around $1168 \mathrm{~mm}$ (FAO, 2005) with the mean monthly discharge at downstream (Athieme station) varies from $261 \mathrm{~m}^{3} \mathrm{~s}^{-1}$ (September) at the peak of the rainy season to about $0 \mathrm{~m}^{3} \mathrm{~s}^{-1}$ in the dry season (February to April). During the rainy season, the rainfall is greater than evapotranspiration (which varies from 4.5 to $6 \mathrm{~mm} \mathrm{~d}^{-1}$; Amoussou, 2014), and vice versa, during the dry season. The basin mean, highest and lowest temperatures are, respectively, 26, 44, and $15^{\circ} \mathrm{C}$. The relative humidity varies between $20 \%-30 \%$ during the Harmattan period in the dry season and $70 \%-80 \%$ during the rainy season (Obahoundje et al., 2018).

\subsection{Data and methods}

The observed rainfall (1961-2016) data for four stations namely Corre-cope, Nangbeto, Tetetou, and Athieme as well as energy generation, inflow, outflow, and water level were obtained from Mono River Authority for 1988-2016. Due to a lack of temperature data, the reanalysis Climate Research Unit (CRU) air temperature data is used. CRU dataset is a month-by-month variation (from 1901 to the present) in climate over the last century and produced by the Climatic Research Unit at the University of East Anglia. CRU data has a spatial resolution of $0.5 \times 0.5^{\circ}$ grids purposely made for climate variation study (New et al., 2002). However, the Thornthwaite (Thornthwaite, 1948) method was used to compute the potential evapotranspiration (PET) based on this CRU temperature data.

An ordinary Kriging method was used to interpolate the observed rainfall from four stations into basin average. Next, the method of Ali and Lebel (2008) was applied to compute the Standardized Precipitation Index (SPI) for the Mono basin. The formula is given by:

$\mathrm{SPI}_{\mathrm{b}}^{i}=\frac{P_{\mathrm{b}}^{i}-\overline{P_{\mathrm{b}}}}{\sigma_{\mathrm{b}}}$

With $P_{\mathrm{b}}^{i}$ the rainfall over basin $\mathrm{b}$ at year $i, \overline{P_{\mathrm{b}}}$ and $\sigma_{\mathrm{b}}$ the mean and standard deviation of the precipitation over basin $b$ for the considered period.

The trend of all variables over the 1988-2016 period was computed using the Mann Kendall test for the Mono basin after an autocorrelation test, all with a significance at $95 \%$ confidence level. The non-parametric Mann-Kendall test which is a rank-based non-parametric test for assessing the significance of a trend (Kendall and Gibbons, 1938) recommended by the World Meteorological Organization (WMO) for trend detection in hydro-meteorological time series (WMO, 2009) is used in this study. The description of the different factors guiding this test is presented in our previous work (Obahoundje et al., 2018).

Finally, the Nangbeto hydropower energy generation's sensitivity analysis was performed using the random forest algorithm. The random forest is proved to be a more reliable sensitivity analysis tool in matching production histories (Aulia et al., 2019) as it gives a robust, internally crossvalidated estimation of the most important variables (Antoniadis et al., 2021). The Mean Decrease Accuracy (\%IncMSE) is then used to determine the most important variables, i.e. those that influence the energy generation the most.

\section{Results and discussion}

\subsection{Sensitivity analysis and correlation}

Figure 2 presents the Mean Decrease Accuracy of all involved variables namely, inflow, water level, rainfall of the current (precip) and the previous (precip_lag1) year, the 


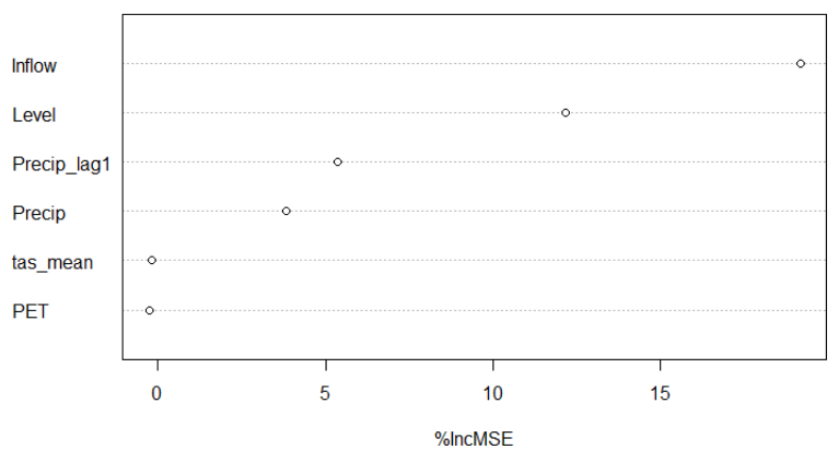

Figure 2. Random Forests-based sensitivity plot of energy generation at Nangbeto dam from 1988 to 2016.

mean temperature, and the potential evapotranspiration. In this figure, the greater the \%IncMSE of a variable, the more the energy is sensitive to that. Thus, the energy generation is found to be more sensitive to inflow to reservoir following by water level. The inflow is found to be strongly and significantly correlated with rainfall, water level, and outflow (Fig. 3). It is also important to highlight that the inflow is derived from river discharge which is a function of hydrological balance (rainfall, PET, runoff) modulated by basin characteristics mainly land use/cover change. The hydropower generation has been shown to be sensitive to both climate variables and land use/cover change in West Africa (Obahoundje et al., 2017, 2021). The water level is controlled by outflow (Fig. 3). The outflow is shown to be strongly and significantly correlated with rainfall, inflow and water level (Fig. 3) and water management policy in place at the dam. For instance, when focusing on rainfall, it was noted that the energy generation is more sensitive to the rainfall of the previous year than rainfall of the current year (Fig. 2). This exhibits the role that water management plays in dam operationalization.

Further analysis confirmed that the energy generation is strongly and significantly correlated with inflow to reservoirs, water level, and rainfall (Fig. 3). The rainfall is also shown to be strongly and considerably correlated with energy, outflow, and inflow. Therefore, the energy generation at the Nangbeto dam is dependent on rainfall.

Furthermore, the Mann Kendall test reveals that only water level (downward) and mean temperature and PET (upward) show a significant trend. It was also shown that water level and inflow are weakly and inversely correlated (not significant) with mean temperature and PET. This increase in PET may contribute to the observed decreasing trend in water level (not significant) and inflow despite the (also not significant) increase in precipitation. Addititionally, the downward trend in inflow could be due decreasing in occurrence of rainfall over Guinea region of West Africa (Bichet and Diedhiou, 2018). This is therefore a consequence of low outflow leading to a (non-significant) decrease in energy production.

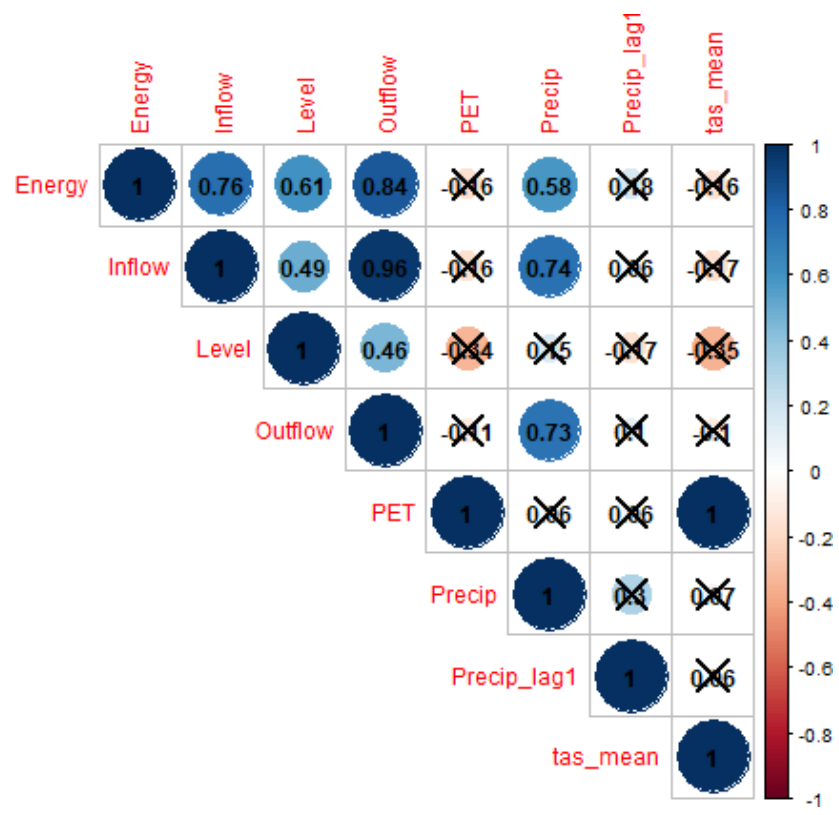

Figure 3. Correlation matric between energy generation and hydroclimatic variables in the Mono river basin. NB: The circle with $\times$ indicates that the correlation is not statistically significant at $95 \%$ confident level while the values are the Pearson correlation coefficient $R$.

\subsection{Interannual variability of rainfall and energy}

The long-term interannual rainfall variability was examined for observed rainfall data over the Mono basin. The 19611995 and 2011-2016 periods were marked by a steady decrease in rainfall while 1996-2011 was affected by an increase in rainfall (not shown). The total annual precipitation amount is greater within the 1961-1980 period than the 1981-2016 period. Generally, two decades (1961-1968 and 2002-2011) exhibit rainfall excess, and the last three (19691980, 1981-1991, and 1992-2001) show a rainfall deficit that affected West Africa in the early 1970s. In addition, the beginning of this last decade and (2012-2016) also exhibit a deficit in rainfall (Fig. 4). However, the 1968-1978 period recorded the lowest rainfall amount over the 1961-1980 period. The basin has recovered from this 1970s drought, but the amount of total rainfall recorded over the last decades as of 1980 is lower than the amount over the 1961-1980 period. This has been proved by different studies in West Africa (Ali and Lebel, 2008; Le Barbé et al., 2002; Diawara et al., 2014; Nicholson, 2013).

The standardized precipitation index (SPI) displays a period merely humid for 1988-2001 and a period globally humid for 2002-2016 (Fig. 4). The SPI analysis reveals that over 29 years (1988-2016) of study, $48.28 \%$ (14 years), $20.69 \%$ (6 years), and $31.03 \%$ (9 years) were respectively normal, dry, and wet years leading to $27.59 \%$ (8 years) of energy generation excess and deficit each. Both periods 1988 2001 and 2002-2016 were made of more normal years. For 


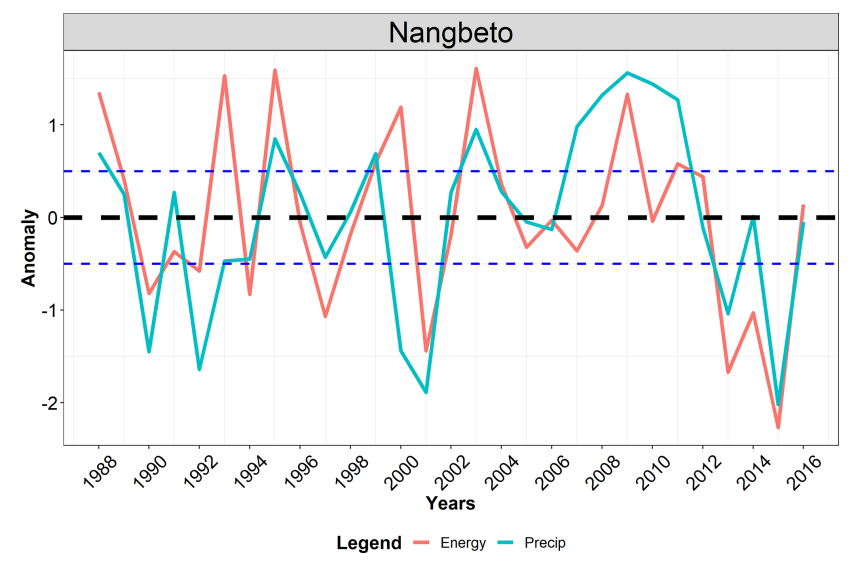

Figure 4. Interannual variability of rainfall and energy anomaly.

instance, $26.67 \%(13.33 \%)$ were with a deficit of rainfall and $20 \%(40 \%)$ were with excess rainfall over the 19872001 (2002-2016) period. The years 2001 and 2015 were the years with the highest deficit while the period 2007-2011 was wet with the highest excess rainfall record. It was noted that energy generation at a given year $(y)$ depends also on the rainfall of the current $(y)$ and/or previous $(y-1)$ year. For instance, the dry year of 1990 led to deficit energy generation in the same 1990 year. The excess energy generation in 2000 despite the dry year 2000 is due to the previous wet year 1999. A higher deficit of energy generation in 2001 is due to consecutive dry years 2000 and 2001. This finding is in the agreement of previous studies in Akosombo in Ghana (Kabo-bah et al., 2016) and Kossou in Ivory Coast dams (Kouame et al., 2019).

\section{Conclusion}

This study evaluates the sensitivity of Nangbeto hydroelectric generation to multi-year hydroclimatic variability using statistical analysis and a random forest model. Energy is noted to be strongly and significantly correlated with inflow; water level is controlled by the climate variable. On the one hand, Nangbeto's hydroelectric generation is more sensitive to inflow and water levels. It was noted that inflow is controlled by precipitation, water level and outflow and also depends on basin characteristics, namely land use and cover change. Water level depends on runoff and water management. In addition, power generation at Nangbeto Dam is sensitive to rainfall in the current and previous years. Therefore, it is suggested that the likely future impacts of climate, basin features and socio-economic development changes on hydropower generation be thoroughly investigated while considering the incidences of climate extreme events as well as compounds extremes.
Code availability. The script written to analyse data during the current study are available from the corresponding author on reasonable request. The statistical analyse was performed used $\mathrm{R}$ language.

Data availability. The datasets generated during and/or analysed during the current study are available from the corresponding author on reasonable request.

Author contributions. SO conducted this research. AD, EA and MYT were the advisors: Conceptualization, SO and AD; Methodology, SO, AD, MYT and EA; Data Curation, LKK and EA; Writing - Original Draft Preparation, SO and AD; Writing - Review and Editing, EA, LKK and MYT; Funding Acquisition, AD.

Competing interests. The contact author has declared that neither they nor their co-authors have any competing interests.

Disclaimer. Publisher's note: Copernicus Publications remains neutral with regard to jurisdictional claims in published maps and institutional affiliations.

Special issue statement. This article is part of the special issue "Hydrology of Large River Basins of Africa". It is a result of the 4th International Conference on the "Hydrology of the Great Rivers of Africa", Cotonou, Benin, 13-20 November 2021.

Acknowledgements. The authors thank the Institute of Research for Development (IRD, France), Institute of Geosciences for Environment (IGE, University Grenoble Alpes) and LAPAMF - African Centre of Excellence on Climate Change, Biodiversity and Sustainable Development (CEA-CCBAD) for providing the facility (the Regional Climate Modelling Platform) to perform this study at the University Felix Houphouët Boigny (Abidjan, Côte d'Ivoire).

Financial support. This research has been supported by the Département Soutien et Formation, Institut de Recherche pour le Développement (UMR IGE Imputation (grant no. 252RA5)) and the Dan David Prize (2019 Dan David Prize Award for Young Researcher).

\section{References}

Ali, A. and Lebel, T.: The Sahelian standardized rainfall index revisited, Int. J. Climatol., 29, 1705-1714, https://doi.org/10.1002/joc.1832, 2008.

Amoussou, E.: Analyse hydrométéorologique des crues dans le bassin-versant du Mono en Afrique de l'Ouest avec un modèle conceptuel pluie-débit, available at: http://www.fmsh.fr (last access: 24 September 2018), 2014. 
Antoniadis, A., Lambert-Lacroix, S., and Poggi, J. M.: Random forests for global sensitivity analysis: A selective review, Reliab. Eng. Syst. Saf., 206, 107312, https://doi.org/10.1016/j.ress.2020.107312, 2021.

Aulia, A., Jeong, D., Saaid, I. M., Kania, D., Shuker, M. T., and El-Khatib, N. A.: A Random Forests-based sensitivity analysis framework for assisted history matching, J. Pet. Sci. Eng., 181, 106237, https://doi.org/10.1016/j.petrol.2019.106237, 2019.

Bichet, A. and Diedhiou, A.: Less frequent and more intense rainfall along the coast of the Gulf of Guinea in West and Central Africa (1981-2014), Clim. Res., 76, 191-201, https://doi.org/10.3354/cr01537, 2018.

Cole, M. A., Elliott, R. J. R., and Strobl, E.: Climate change, hydrodependency, and the african dam boom, World Dev., 60, 84-98, https://doi.org/10.1016/j.worlddev.2014.03.016, 2014.

Diawara, A., Yoroba, F., Kouadio, K. Y., Kouassi, K. B., Assamoi, E. M., Diedhiou, A., and Assamoi, P.: Climate variability in the Sudano-Guinean transition area and its impact on vegetation: The case of the Lamto region in Côte D'Ivoire, Adv. Meteorol., 2014, 11, https://doi.org/10.1155/2014/831414, 2014.

FAO: L'irrigation en Afrique en chiffres - Enquête AQUASTAT 2005, Food \& Agriculture Organisation, Rome, 2005.

Hamududu, B. and Killingtveit, A.: Assessing climate change impacts on global hydropower, Energies, 5, 305-322, https://doi.org/10.3390/en5020305, 2012.

Hamududu, B. H. and Killingtveit, A.: Hydropower production in future climate scenarios; the case for the Zambezi River, Energies, 9, 1-18, https://doi.org/10.3390/en9070502, 2016.

IHA: Hydropower Status Report 2018, International Hydropower Association, Benjing, 2019.

Kabo-bah, A., Diji, C., Nokoe, K., Mulugetta, Y., ObengOfori, D., and Akpoti, K.: Multiyear Rainfall and Temperature Trends in the Volta River Basin and their Potential Impact on Hydropower Generation in Ghana, Climate, 4, 49, https://doi.org/10.3390/cli4040049, 2016.

Kendall, M. and Gibbons, J. D.: Rank correlation methods, 5th edn., edited by: Arnold, E., Oxford University Press, New York, NY, London, C1990, available at: https://trove.nla.gov.au/work/3478976?q\&sort=holdings+ desc\&_=1532491936434\&versionId=21204985 (last access: 22 August 2018), 1938.

Kling, H., Stanzel, P., and Fuchs, M.: Regional Assessment of the Hydropower Potential of Rivers in West Africa, Energ. Proced., 97, 286-293, https://doi.org/10.1016/j.egypro.2016.10.002, 2016.

Kouame, Y. M., Obahoundje, S., Diedhiou, A., François, B., Amoussou, E., Anquetin, S., Didi, R. S., Kouassi, L. K., N'guessan Bi, V. H., Soro, E. G., and Yao, E. K.: Climate, Land Use and Land Cover Changes in the Bandama Basin (Côte D'Ivoire, West Africa) and Incidences on Hydropower Production of the Kossou Dam, Land, 8, 103, https://doi.org/10.3390/land8070103, 2019.
Le Barbé, L., Lebel, T., and Tabsoba, D.: Rainfall Variability in West Africa during the Years 1950-90, J. Climate, 15, 187-202, https://doi.org/10.1175/15200442(2002)015<0187:RVIWAD>2.0.CO;2, 2002.

New, M., Lister, D., Hulme, M., and Makin, I.: A high-resolution data set of surface climate over global land areas, Clim. Res., 21, 1-25, https://doi.org/10.3354/cr021001, 2002.

Nicholson, S. E.: The West African Sahel: A Review of Recent Studies on the Rainfall Regime and Its Interannual Variability, ISRN Meteorol., 2013, 1-32, https://doi.org/10.1155/2013/453521, 2013.

Obahoundje, S., Ofosu, E., Akpoti, K., and Kabo-bah, A.: Land Use and Land Cover Changes under Climate Uncertainty: Modelling the Impacts on Hydropower Production in Western Africa, Hydrology, 4, 2, https://doi.org/10.3390/hydrology4010002, 2017.

Obahoundje, S., Diedhiou, A., Ofosu, E. A., Anquetin, S., François, B., Adounkpe, J., Amoussou, E., Kouame, Y. M., Kouassi, K. L., Nguessan Bi, V. H., and Ta, M. Y.: Assessment of Spatio-Temporal Changes of Land Use and Land Cover over South-Western African Basins and Their Relations with Variations of Discharges, Hydrology, 5, 56, https://doi.org/10.3390/hydrology5040056, 2018.

Obahoundje, S., Youan Ta, M., Diedhiou, A., Amoussou, E., and Kouadio, K.: Sensitivity of Hydropower Generation to Changes in Climate and Land Use in the Mono Basin (West Africa) using CORDEX Dataset and WEAP Model, Environ. Process., 8, 1073-1097, https://doi.org/10.1007/s40710-021-00516-0, 2021.

Riede, J. O., Posada, R., Fink, A. H., and Kaspar, F.: What's on the 5th IPCC Report for West Africa?, in: Adaptation to Climate Change and Variability in Rural West Africa, edited by: Yaro, J. A. and Hesselberg, J., 7-23, Springer International Publishing, Switzerland, 2016.

Rim, B.: Energies renouvelables en Afrique: Enjeux , défis et opportunités, Policy Center for the New South, Maroc, 2019.

Thornthwaite, C. W.: On the deformation mechanisms in sap single crystals, Geogr. Rev., 38, 55-94, https://doi.org/10.1016/00223115(71)90076-6, 1948.

WMO: Extreme Values Analysis in The Guide to Hydrological Practices, vol. II, in: Management of Water Resources and Application of Hydrological Practices, World Meteorological Organization, Switzerland, 2, 302 pp., 2009. 